\title{
Short Note \\ Desiccation resistance of Antarctic Dry Valley bacteria isolated from contrasting locations
}

\author{
LEWIS R. DARTNELL ${ }^{1,2 *}$, DAVID R. FALLAIZE ${ }^{1,2}$, SAMANTHA J. WHITING ${ }^{\mathbf{2}}$ and JOHN M. WARD ${ }^{2}$ \\ ${ }^{I}$ Centre for Mathematics and Physics in the Life Sciences and Experimental Biology (CoMPLEX), University College London, \\ Gower Street, London WC1E 6BT, UK \\ ${ }^{2}$ Research Department of Structural and Molecular Biology, University College London, Gower Street, London, WC1E 6BT, UK \\ *l.dartnell@ucl.ac.uk
}

Received 3 July 2009, accepted 5 October 2009

\section{Introduction}

The McMurdo Dry Valleys of Antarctica exhibit extensive areas completely devoid of ice and are extremely inhospitable to life (Cowan et al. 2002), yet many organisms are known to survive loss of virtually all their cellular water (Billi \& Potts 2002). This study aims to investigate the link between desiccation resistance and the microhabitat of Antarctic bacteria testing if bacteria from a more sheltered habitat will exhibit lower desiccation resistance than bacteria from an exposed location. In addition, Deinococcus radiodurans Brooks and Murray is used as model desiccation-resistant organism, in contrast to Escherichia coli, a human enterobacterium with no adaptive requirement for desiccation-resistance.

\section{Materials and methods}

Samples of Miers Valley soil were collected in February 2002 from beneath a dead algal mat surrounding a small frozen lake and the desiccated mineral soil from the valley floor representing a sheltered and organic nutrient-rich niche, and a more exposed oligotrophic environment, respectively. Samples were below $0^{\circ} \mathrm{C}$ until $1-2 \mathrm{~g}$ of soil were vortexed with an equal volume of sterile water and $50 \mu$ l volumes then spread on quarter-strength nutrient broth agar $\left(\frac{1}{4} \mathrm{NB}\right.$; CM0001 Nutrient Broth, Oxoid, $3.25 \mathrm{~g}$ and $20 \mathrm{~g}$ agar per 11 deionised water), starch agar ( $5 \mathrm{~g}$ per 1 potato starch; Sigma and $20 \mathrm{~g}$ per 1 agar), quarter-strength Czapek-Dox agar $\left(8.75 \mathrm{~g}^{-1} \mathrm{CZD}\right.$, Difco and $20 \mathrm{~g}$ per 1 agar), and plates incubated at $4^{\circ} \mathrm{C}$. Pure isolates were obtained by subculturing individual colonies two further times. Subsequent investigation found that isolates also grew well at room temperature.

\section{Identification of isolated bacteria}

Single colonies were picked by sterile loop, resuspended in $20 \mu \mathrm{l}$ of sterile water, heated to $95^{\circ} \mathrm{C}$ in a thermocycler, then centrifuged. A $1 \mu \mathrm{l}$ volume of the supernatant was used as the template for a polymerase chain reaction (PCR) with Taq polymerase. Primer set CC/CD (Rudi 1997) was selected to amplify a $\sim 600 \mathrm{bp}$ region of the bacterial $16 \mathrm{~S}$
rRNA gene. PCR products were purified using the QIAquick PCR Purification Kit (Qiagen) and ligated into the pCR2.1 vector with the TOPO ${ }^{\circledR}$ TA cloning kit (Invitrogen). A vial of OneShot ${ }^{\circledR}$ chemically competent $E$. coli cells (Invitrogen) were transformed and then plated onto selective media. Recombinant colonies were picked and grown in liquid medium, then plasmids extracted using QIAprep Spin Miniprep Kit (QIAGEN). Recombinant pCR2.1 containing the $16 \mathrm{~S}$ rRNA gene inserts were sequenced using vectorspecific primers M13F and M13R (Pearce et al. 2003). Identification of each isolate based on its $16 \mathrm{~S}$ rRNA gene sequence was confirmed using both the Ribosomal Database Project, RDP, (http://rdp.cme.msu.edu) and BLASTn (NCBI) sequence search utility (www.ncbi.nlm.nih.gov/BLAST).

\section{Desiccation survival}

Pseudomonas sp. and Psychrobacter sp., from beneath the algal mat, Bacillus sp. and Streptomyces sp., from the exposed valley floor, and D. radiodurans and E. coli Top10 were streaked onto sterile agar plates. A single colony was picked to inoculate $\frac{1}{4} \mathrm{NB}$ (Oxoid) liquid cultures, and incubated with constant agitation at room temperature for three days. $100 \mu \mathrm{l}$ samples of each liquid culture were pipetted into ten separate $35 \mathrm{~mm}$ Falcon tissue culture dishes, and stacked in sterilized air-tight Nalgene tubs over $2 \mathrm{~cm}$ of granulated anhydrous calcium chloride as a desiccant. In addition, a control dish containing $100 \mu \mathrm{l}$ of sterile $\frac{1}{4} \mathrm{NB}$ was prepared in the same way as a check for contamination. After set time periods, culture dishes were removed and rehydrated with $1 \mathrm{ml}$ phosphate buffer solution (PBS; Sigma), agitated for ten minutes on an oscillating table at 20 oscillations/minute. A colony forming unit (CFU) assay was performed in triplicate on the pre-desiccation cultures and each recovered sample of rehydrated bacteria solution. The ratio of viable cells in the rehydrate to original culture gives the population desiccation survival, corrected for the $90 \%$ efficiency of culture rehydration and recovery found here.

\section{Results and discussion}

On the $\frac{1}{4} \mathrm{NB}$ agar cultures, initial plate counts found a total of $8 \times 10^{3}$ cells.g ${ }^{-1}$ wet wt from beneath the algal mat and 


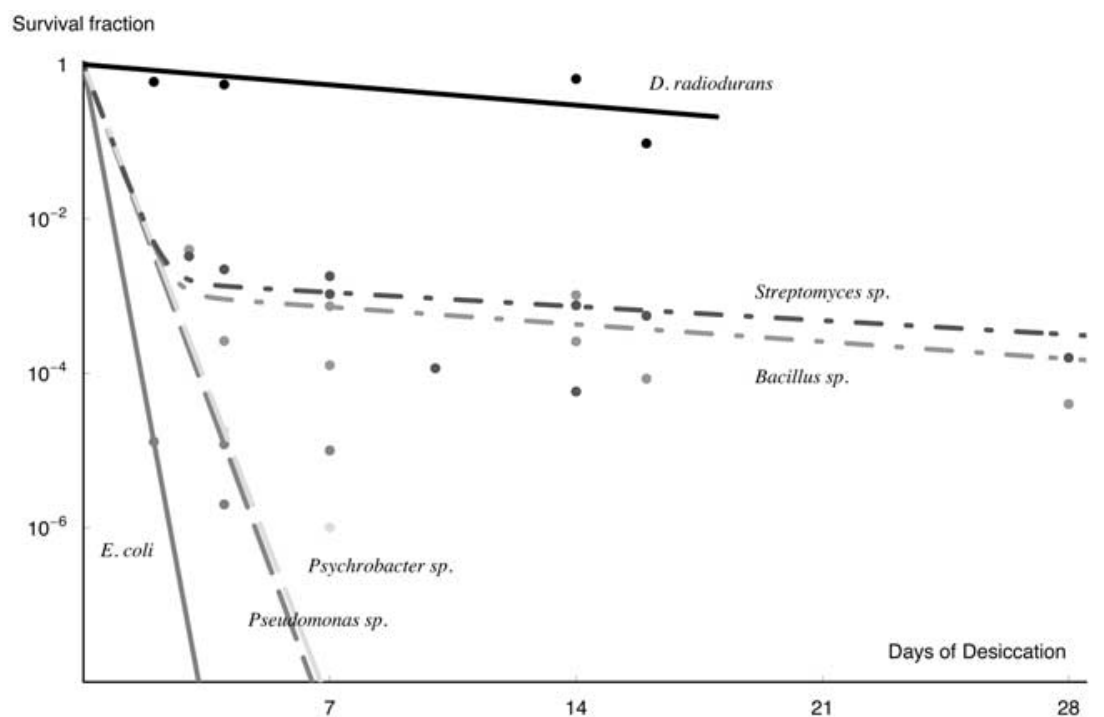

Fig. 1. The surviving fraction of bacterial populations against time spent desiccated. Sampling regions: dashed line $=$ beneath an algal mat, dot-dash line $=$ exposed valley side. Double-exponential trend lines fitted to Streptomyces and Bacillus, exponential trends to all others.
$6 \times 10^{2}$ cells g $^{-1}$ wet wt from the exposed sampling location. Gram negative bacteria were dominant beneath the algal mat (9/12 isolates from all media types), with all isolates from non-spore-forming genera, and Gram positive bacteria were dominant in the exposed sample (11/12 isolates), with $5 / 12$ strains spore-forming. The strains used for this desiccation study were thus selected as characteristic species from each sampling location. Bacillus, Pseudomonas, and Streptomyces are among the most commonly isolated bacterial genera from the McMurdo Dry Valley soils (Cowan \& Tow 2004), and Psychrobacter aquatica Shivaji was originally isolated from the Dry Valleys (Shivaji et al. 2005).

Figure 1 shows the proportion of surviving cells as a function of desiccation time, colour-coded for the sampling locations to make clear the correlation between microhabitat and desiccation survival. After a week of desiccation, viability of the two algal mat species is undetectable $(<10$ viable cells in the $100 \mu \mathrm{l}$ of desiccated culture). In contrast, isolates from the exposed location initially lose viability but soon plateau at around one in $10^{4}$ survival up to the full 28 days of desiccation. Deinococcus radiodurans exhibits the greatest resistance of all six test strains, with roughly $60 \%$ survival at up to two weeks desiccation, whilst $E$. coli shows very poor survival.

These results support the prediction that Antarctic Dry Valley bacteria isolated from a more barren and exposed location exhibit much greater desiccation resistance than those adapted to more a more sheltered microenvironment.

\section{Acknowledgements}

L.R. Dartnell and D. Fallaize were supported by an EPSRC Doctoral Training Centre studentship. S.J. Whiting was supported by a BBSRC PhD studentship.

\section{References}

Billi, D. \& PotTs, M. 2002. Life and death of dried prokaryotes. Research in Microbiology, 153, 7-12.

Cowan, D., Russell, N., Mamais, A. \& Sheppard, D. 2002. Antarctic Dry Valley mineral soils contain unexpectedly high levels of microbial biomass. Extremophiles, 6, 431-436.

Cowan, D. \& Tow, L.A. 2004. Endangered Antarctic environments. Annual Review of Microbiology, 58, 649-690.

Pearce, D.A., Gast, C.J., Lawley, B. \& Ellis-Evans, J.C. 2003. Bacterioplankton community diversity in a maritime Antarctic lake, determined by culture-dependent and culture-independent techniques. FEMS Microbiology Ecology, 45, 59-70.

Shivaj,, S., Reddy, G.S.N., Suresh, K., Gupta, P., Chintalapati, S., Schumann, P., Stackebrand, E. \& Matsumoto, G.I. 2005. Psychrobacter vallis sp. nov. and Psychrobacter aquaticus sp. nov., from Antarctica. International Journal of Systematic and Evolutionary Microbiology, 55, 757-762. 